\title{
Peers, Mentors, and University Educators Assessing Science Student Teachers during School-Based Practicum: Whose Assessment Matters?
}

\author{
Fhatuwani J. Mundalamo \\ Thomas D. T. Sedumedi \\ Department of Mathematics, Science and Technology Education, \\ Tshwane University of Technology, Pretoria, South Africa \\ MundalamoFJ@tut.ac.za \& Sedumeditdt@tut.ac.za
}

Doi:10.5901/mjss.2014.v5n20p1782

\begin{abstract}
In this paper, we explore the assessment practices of peers, school-based mentors, and university educators during teaching practicum for students registered at a South African university. Student teachers in their second year of Bachelor of Education study were assessed while teaching a science lesson at a school during practicum. Each of the assessors observed a student teacher teaching a separate lesson and the comments were recorded in a teaching journal. Using a coding system, we analyzed all the assessors' comments recorded in 53 journals. The analysis indicates that the assessors focused on four areas of teaching knowledge, i.e. praising of student teacher, learner knowledge, teaching strategy, and subject matter knowledge. Although there were some differences in the way the assessors assessed these knowledge areas, we suggest that all assessors should undergo some training before assessing student teachers. Because their comments were mostly focused on praising student teachers during the teaching practicum, we also suggest that peers should only assess for formative purposes during practicum. Mentors and university teacher educators should be the only people assessing student teachers for both formative and summative purposes.
\end{abstract}

Keywords: Assessment; Teaching Practicum; Mentor; Peer; and University Educator

\section{Introduction}

Assessment forms an integral part of teaching practicum and an indispensable activity in teacher preparation. Assessment of practicum ensures that when student teachers graduate they are ready to enter the teaching profession with some amount of relevant practical knowledge. Student teachers in one of the South African universities undergo a six-week teaching practicum while in their first, second, and third year of a Bachelor of Education qualification. In their fourth year of study, they do a full semester teaching practicum from July until the end of the school-term in December. First-year student teachers spend six weeks of the teaching practicum observing qualified schoolteachers teaching. They also engage in extramural activities such as assisting in athletics.

In their second year of study, student teachers teach one of their two major teaching subjects. Their assessors record all their assessments in a teaching journal. There are three types of assessors for each student teacher, namely peers, mentors and university lecturers. The peers' assessments only contribute to the development of student teachers; their marks are not recognized for grading purposes.

Student teachers are assigned to schoolteachers (mentors) who mentor them during practicum. As a requirement by the university, mentors also assess student teachers' lesson presentation. In most cases, these mentors would observe student teachers' lessons and provide advice for improvement where necessary. The student teachers' teaching journals include a space for the mentors to record their comments after evaluating a lesson presentation. This assessment is also not considered for the final grading of a student teacher. The marks they award therefore serve the purpose of evaluating the level of development of the teachers' pedagogical skills.

A university teacher educator assesses student teachers' lesson presentations once per teaching practicum. Although this paper focuses on how the science (Mathematics, Biology, and Physical Science) student teachers in this study were assessed, the majority of their assessors (including university educators) were not qualified in the science field. The university educators record their assessment comments in the same journal as peers and mentors. In most cases, the university educators are the last to observe the student teachers' lessons, and therefore they are at liberty to reflect on the appraisals of other assessors. This paper aims to establish the areas peers, mentors and university 
educators mostly assess. In addition, it indicates relationships between areas the three assessor groups assessed. We then deliberate on how best the assessors could work together to ensure optimal benefits of assessment for student teachers.

\section{Theoretical Background}

A student teacher who is teaching for the first time during practicum expects to perform in a certain way. However, this kind of expectancy can change during the actual lesson depending on contextual factors. Such factors are magnified by the presence of a third person such as an assessor. Fung and Chow (2002) and Ezer, Gilat and Sagee (2010) suggest that teacher educators should play a major role in making sure that student teachers understand the differences between their intended images and the actual images for teaching a class during teaching practicum. For the teaching practicum to produce quality teachers (Ezer et al., 2010), there needs to be assessment to judge the student teacher. For such quality to prevail, it should be preceded by "a strong partnership between schools, education faculties and student teachers" (Taskin, 2006, p.397). Such a partnership should ensure that whatever method of assessment is used to evaluate student teachers during practicum, it should also be of greater quality (Tang, 2008). This is even more relevant in this study, where we investigated what emerged from the three assessors' judgements of student teachers' lessons. What transpires in these formative (peer, and mentor) and summative (university educator) assessments should still "serve purposes of gatekeeping or control of entry into the profession" (Orland-Barak, 2002, p.101).

Student teachers consider teaching practicum as the most important activity in their study programmes (Poulou, 2007; Brooker, Muller, Mylonas \& Hansford, 1998). The practicum serves a larger purpose than merely as the bridge between theory and practice (Smith \& Lev-Ari, 2005; Bailey, Scantlebury \& Johnson, 1999). Student teachers are in a difficult position (Fives, Hamman \& Olivarez, 2007) because "their knowledge of pedagogy and child development is still naïve" and they are required to act as "both student and teacher" (p.916). Because of these demands on student teachers, they may experience anxiety (Murray-Harvey, Slee, Lawson, Silins, Banfield \& Russell, 2000). Although student teachers in a study conducted by Sinclair and Nicoll (cited in Fives et al., 2007) saw teaching practicum as the final assessment of their teaching abilities, this is not applicable in this study. In this study student teachers were in their second year of a four-year degree programme. They regarded this assessment as an instrument to judge the development in their teaching skills.

Feedback has become a highly valued component of professional development for both experienced professionals and student teachers (Smith \& Lev-Ari, 2005; Smith, 2007). Tang (2008) suggests that university educators and mentors can judge student teachers well, especially if they interact with and observe student teachers over an extended period. Depending on the needs of the teacher training programme, summative or formative assessment or both may be preferred. Formative assessment uses "evidence to inform the next steps of learning in relation to the progress" made towards the set learning goals, while summative assessment interprets evidence by "summarizing what has been achieved" (Tang, 2008, p.20). Student teachers should be made aware of these types of assessment or their purposes and mentor teachers or university educators should explain assessment criteria to the students (Brooker et al., 1998). This ensures that discrepancies "between stated and assessed goals" (Brooker et al., 1998, p.10) are reduced. For any critique to be acceptable to student teachers, enough evidence should accompany it (Bailey et al., 1999).

\subsection{The assessors}

Mentoring is reported to be a useful strategy for supporting teacher educators (Ulvik \& Sunde, 2012) Mentors help student teachers to assimilate into the profession (Patrick, 2013). The roles of mentors are varied (Kirbulut, Boz \& Kutucu, 2012). They provide student teachers "with positive and beneficial experiences" ( $p .41)$ that "allow student teachers to experiment with new teaching methods while teaching" (p.41). In fact, student teachers indicate that the mentor teacher is their main influence on their later teaching style (Bailey et al., 1999). Besides providing direction to the student teacher's learning, the mentor teacher may observe and then assess the student teacher's activities during practicum (Fives et al., 2007). In Gemmell and Long's study cited in Kirbulut et al. (2012), mentors reported to student teachers that "their teaching was fine, even if it was not" (p.42). Comments such as these create suspicion about what exactly was assessed. Of course, this may not happen if mentors are prepared for their roles (Ulvik \& Sunde, 2013).

Some student teachers view teaching practicum as the best way of acquiring professional knowledge and becoming competent teachers (Leshem, 2012). They trust the competence of their mentors during practicum to the extent that they "relinquish their own views about teaching practices out of respect to the mentor's knowledge and experience" (p.418). Student teachers consider their mentor teachers as experts and are keen to emulate their teaching strategies 
(Hascher, Cocard, \& Moser, 2004). Peer interactions during teaching practicum, specifically during peer assessment, help student teachers to recognize gaps in their development of professional knowledge (Manouchehri, 2002). This benefit becomes more amplified and facilitates the understanding of content and teaching issues if the student teacher and his/her peer also collaborate during planning and analysis of lessons (Manouchehri, 2002). A student teacher in Taskin's (2006) study "stated that the presence of other student teachers in the classroom had positively influenced her teaching and the classroom environment" (p.394). In their study, Harford and MacRuairc (2008) chose for their sample student teacher peers based at the same school during practicum with the same subject specialism/ teaching subject. In the present study, however, the pairs did not fully satisfy these criteria, given that student teachers and their peers were not necessarily teaching the same subject.

The roles of university educators include, amongst others, guidance, support, assessing and evaluating student teachers' performance and acting as gatekeepers to the profession (Hyland \& Lo, 2006). The university educator who visits biweekly for observations and discussions (Fives et al., 2007) can support student teachers. In a study by Brooker et al. (1998), the university educator served as liaison between the faculty and the school and "as a moderator between student and teacher when such action" was required (Brooker et al., 1998, p.11).

\subsection{Assessment in practicum}

In their study, Ezer et al. (2010) reported that student teachers who graduated perceived "the practical work [teaching practicum] and the didactic classes as more important to their training than the classes on discipline subject matter or classes on education" (p.402). This cannot be generalized for other teacher training programmes throughout the world. In their study, Smith and Lev-Ari (2005) reported that student teachers appreciated "becoming knowledgeable in the subject matter" (p.300). Ezer et al. (2010) further report that "both the didactic instructor and the mentor teacher are perceived as making a greater contribution than the subject matter teachers and those who teach education and auxiliary subjects" (p.402). It is in light of these experiences that assessment for teacher preparation be holistic.

\section{Statement of the Problem}

Teaching practicum at this particular South African university is assessed by peers, mentors and university educators. In a previous study (Sedumedi \& Mundalamo, 2012) conducted at the same university researchers show that non-subject specialists who assessed another cohort of student teachers commented mostly on classroom management, pedagogical skills and learner knowledge. The mentors were reported to focus on classroom management and praising of student teachers. Peer assessors (Sedumedi \& Mundalamo, 2012) "did not comment on learner knowledge, subject matter knowledge and pedagogical skills" (p.S85). It is not clear whether assessors' contributions individually assist in the development of a student teacher to become a fully qualified practising teacher. For that reason, we embarked on content analysis of all comments made by the three assessor groups. This was done to gather detailed information embedded in each comment and to determine the strength and weakness of each group and see how those can be brought together to benefit teaching practicum.

\section{Research Questions}

\subsection{Research Question 1:}

What are the key pedagogical issues that emanate from the peers', mentors', and university educators' assessment of the student teachers' teaching practice?

\subsection{Research Question 2:}

Whose assessment is important in making sure that the student teacher develops into a quality teacher?

\section{Methodology}

\subsection{Sampling}

This study focuses on teaching practicum at a South African university. The population consists of all student teachers 
registered for the second-year level of a four-year Bachelor of Education degree. The sample considered for this study comprised 53 student teachers who were each majoring in two of the following subjects: Mathematics, Biology, and Physical Science. The student teachers spent six weeks in teaching practice where they taught one of their majors. Each student teacher was assessed by a peer whose major subjects were not necessarily the same as those of the student teacher, a mentor who was a subject specialist teacher based at the particular school, and a university educator who in most cases was not a subject specialist.

\subsection{Data analysis}

Each student teacher has a journal in which all the assessors' comments are recorded after they have each awarded a mark per instrument in the journal. The marks and comments by mentors and peers are not considered for summative assessment. In this study, all the assessors' comments at the end of their evaluation in the journal were re-written in MSWord. Each assessor's comments were recorded under his/her pseudonym, viz., Mentor 1 or M1, Peer 2 or P2, University educator 53 or U53. The comments were then read for identification of codes related to teaching. The data was then grouped together under the same code, still with the assessor as identifier of the source. The frequencies for each code were counted and recorded in Table 1 below. The qualitative data was then discussed under each code.

\section{Results}

In this study, we regarded any frequency above $50 \%$ as a significant contribution coming from any group of assessors. Data analysis reflected that there were only four areas of teaching knowledge emphasized by assessors during their assessments. These areas were praising student teacher (PST), learner knowledge (LK), teaching strategy (TS), and subject matter knowledge (SMK).

Mentors ranked the highest (47 out of a possible 53) for praising student teachers for being "very good" in teaching. A greater percentage of mentors who praised the student teachers indicated that they were good while a smaller percentage criticised the way they taught. Thirty-three (33) peers praised or criticised the student teachers' presentations. Less than half of the university educators either praised or criticised the student teachers' presentations.

Generally, the same number of frequencies for the item learner knowledge for both university educators (31) and mentors (30) out of a possible fifty-three (53) for each emanated from the data. Peers scored the lowest frequency of twenty (20) for learner knowledge.

The item teaching strategy received the highest frequency from the university educators (76/53), while mentors and peers scored 28 and 24 (less than 50\%) respectively. Only university educators scored a total frequency greater than $50 \%$ (i.e. $51 \%$ ) on the item subject matter knowledge.

Both peers, mentors, and university educators scored frequencies below $50 \%$ for items classroom management (CM), link to previous lesson or prior knowledge (LTL), lesson plan (LPN), syllabus/curriculum (SC), time management (TM), voice level (VL), introduction of lesson (INT), student teacher's appearance (STA), lesson presentation (LP), media usage, assessment (AS), and language (LAN).

Table 1: University educators', mentors', and peers' frequencies from comments made after observing student teachers during teaching practicum

\begin{tabular}{|l|c|c|c|c|}
\hline Items & $\begin{array}{c}\text { University educators } \\
\mathbf{N = 5 3}\end{array}$ & $\begin{array}{c}\text { Mentors } \\
\mathbf{N}=53\end{array}$ & $\begin{array}{c}\text { Peers } \\
\mathbf{N}=53\end{array}$ & $\begin{array}{c}\text { Total (percentage in brackets) } \\
\mathbf{N}=159\end{array}$ \\
\hline Praising Student Teacher (PST) & 24 & 47 & 33 & $104(65 \%)$ \\
\hline Learner Knowledge (LK) & 31 & 30 & 20 & $81(51 \%)$ \\
\hline Teaching Strategy (TS) & 76 & 28 & 24 & $128(81 \%)$ \\
\hline Subject Matter Knowledge (SMK) & 27 & 14 & 10 & $51(32 \%)$ \\
\hline Classroom Management (CM) & 13 & 9 & 14 & $36(22 \%)$ \\
\hline $\begin{array}{l}\text { Link to Previous Lesson or Prior Knowledge } \\
\text { (LTL) }\end{array}$ & 10 & 7 & 13 & $30(19 \%)$ \\
\hline Lesson Plan (LPN) & 18 & 8 & 6 & $32(20 \%)$ \\
\hline Syllabus/ Curriculum (SC) & 0 & 6 & 0 & $6(4 \%)$ \\
\hline Time Management (TM) & 3 & 4 & 3 & $10(6 \%)$ \\
\hline Voice Level (VL) & 2 & 4 & 11 & $10(6 \%)$ \\
\hline Introduction of Lesson (INT) & 14 & & $29(18 \%)$ \\
\hline
\end{tabular}




\begin{tabular}{|l|c|c|c|c|}
\hline Student Teacher's Appearance (STA) & 4 & 3 & 1 & $8(5 \%)$ \\
\hline Lesson Presentation (LP) & 19 & 1 & 18 & $38(24 \%)$ \\
\hline Media Usage (MU) & 22 & 2 & 7 & $31(19 \%)$ \\
\hline Assessment (AS) & 26 & 1 & 0 & $27(17 \%)$ \\
\hline Language (LAN) & 5 & 0 & 4 & $9(6 \%)$ \\
\hline
\end{tabular}

We discuss the results in detail in the next section (Discussion of Results).

\section{Discussion of Results}

\subsection{Praising of student teachers (PST) by mentors, peers, and university educators}

Mentors praised student teachers more (47/53) than peers (33/53) and university educators (24/53). This means that each of the fifty-three teachers praised the student teacher they observed. Also, the frequency for peers indicates that out of fifty-three peers, only twenty did not praise the student teachers observed, while twenty-nine university educators did not praise the student teachers they observed. PST ranks the highest for mentors in comparison with the other items. We indicate below how PST is subdivided into codes that emanated during analysis.

\subsubsection{Well-presented lesson}

A larger percentage (10/47) of mentors' praise was in relation to how the lesson was presented. Some of the comments that are representative of the rest in this group are as follows:

\section{M4: "Well done. Your presentation was very good!!" \\ M9: "Educator presents lesson very well." M19: "Well presented lesson"}

It is not certain what the mentors meant by reporting to the student teachers that their lesson/ presentation was either "very good", "well presented" or "interesting". We are not convinced, however, that student teachers who are teaching officially for the first time during teaching practicum will understand or know exactly which sections of their presentation were "well presented". The report in this paper is not the first about mentors 'empty praising' their mentees. In a study conducted by Gemmell and Long cited in Kirbulut et al. (2012), mentors reported to student teachers that "their teaching was fine, even if it was not" ( $p .42)$. Student teachers, as in any other practice, cannot be 'very good' when they are just starting their profession. Even if they are 'good' there should be something about their presentation that could or should be improved. When such areas for improvement are not indicated, we doubt if the mentors' comments serve to develop the future teachers.

A few peers indicated that the lessons were well presented and that one of the peers was a 'hard worker'. The following comment provided by the peer to a student teacher may confuse him/ her:

\section{P29: "Otherwise the lesson was well presented. Keep it up!"}

The student teacher will surely not know where in the lesson he/she is supposed to improve.

The university educators' praise was also dominated by 'empty praises', for example:

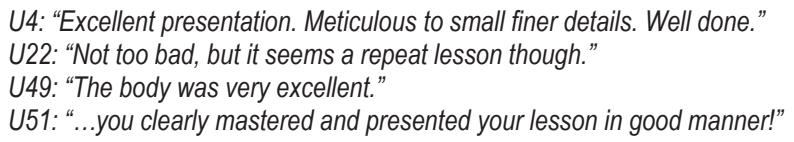

U4: "Excellent presentation. Meticulous to small finer details. Well done."

U22: "Not too bad, but it seems a repeat lesson though."

U49: "The body was very excellent."

U51: "...you clearly mastered and presented your lesson in good manner!"

All these comments fail to indicate directly which section of the presentation was well presented. The university educators would point out exactly where the student teacher performed well if they themselves were qualified in the subject the student teachers were presenting. At this university however, a large number of university educators who assess student teachers do so without the knowledge of the subject taught by the student teachers, and therefore it is easier for them to only say "The body was very excellent". 


\subsubsection{Introduction and fun lesson}

Only one mentor commented about the student teacher's introduction of the lesson presentation. The mentor however did not indicate what exactly was 'good' about the introduction. The student teacher received a 'well done' comment. There was also one comment from a mentor about a lesson being 'fun'. The peers and university educators did not contribute in these two sub-items.

\subsubsection{Good lesson}

Very few assessors praised student teachers in terms of delivering a 'good lesson'. These comments make student teachers happy, although they may not know what it means to deliver a 'good lesson'. The student teachers were teaching for the first time during teaching practicum. They therefore could not deliver a spotless 'good lesson' without gathering enough teaching experience.

\subsubsection{Well-prepared lesson}

Mentors were the only assessors who praised student teachers in terms of a 'well-prepared lesson'. Is it because they spend some time with student teachers at school or because they are responsible for assisting student teachers to draw up lesson plans? Although the well-prepared lesson appears four times in the mentors' comments, these comments came from two mentors only. We therefore cannot take this as representative of all the mentors. The fact that they were the only assessors who mentioned 'well-prepared lesson' may mean the two mentors had some interest in the development of student teachers' lessons.

\subsubsection{Language}

One mentor who praised a student teacher for a 'Good presentation' warned the student teacher about the use of language. S/He indicated that there was a "problem with pronunciation". This made the comment a useful one, because the student teacher would know that not everything was good about his/ her presentation.

\subsubsection{Very good/ excellent teacher}

The comments by mentors, peers, and university educators in this sub-section formed a significant proportion/percentage of all the expressions of praise made by all the assessors. The praise was more focused on student teachers themselves and not their lesson presentations. For example, they would indicate the following:

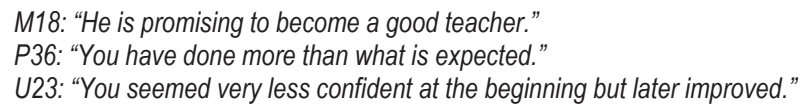

These comments show that the assessors did not focus on the lesson presentation when they praised the student teacher. The comments were more about the present (is a good teacher) or the future state (promising to become a good teacher) of student teachers. In contrast, a comment by a university educator U23 (see above) shows that the assessor evaluated the student teacher throughout the lesson. All the other commendations failed to address student teachers' teaching development concerns.

\subsubsection{Outside classroom praises}

The mentors' comments concerning how the student teachers conducted themselves outside the classroom were focused on respect for others, dedication, passion and being a good future teacher. Some of their comments were as follows:

M16: "...he is too cooperative ... and listens to other people's advice. ... that even if he can be employed he will do the best and he seems to be a good future educator."

M24: "She shows passion of this job. So far you got what it takes to become a good teacher. ... always dedicate herself in each and every lesson." 
M52: "... excellent educator takes pains to seek information and help. Professional conduct always excellent."

The above comments also show that mentors, unlike university educators, go beyond merely observing one lesson presentation of student teachers. They continually interact with them, and that is why they are able to comment about things that happen outside the lesson presentation.

Peers are more focused on the future of the student teachers as teachers, although the student teachers are still in their second year of study. Some of their comments are as follows:

P26: "He is showing competency on whatever he is doing. He will make a very good teacher in the near future."

P31: "Keep it up!!! You will be a good teacher in future."

Comments not directly related to the classroom were not common from university educators, although one of them said:

\section{U47: "You are energetic! You will be a great teacher!"}

We do not agree with his/ her statement that if you are energetic you can be successful. The student teacher may take this comment seriously and be more energetic in the next lesson without any other improvement in the lesson presentation. This statement can mislead a student teacher.

\subsection{Learner knowledge (LK)}

Most teacher education programmes expect to produce teachers who, in addition to being knowledgeable (Smith \& LevAri, 2005), also "master the more technical aspects of teaching such as classroom management, working with children of diversity, and good lesson planning" (p.290).

Some mentors that commented on issues relating to learner knowledge praised student teachers for making sure that there was learner interaction and the class was not learner centred. Some mentors indicated areas that they thought student teachers should improve on, for example:

\footnotetext{
M48: "Try to dig information from learners continuously to see if they follow what you're presenting. Some learners lose interest while you busy telling."

M9: "...and learners are participating. Many participated but have to be called by their names. Educator should not accept group answers."

M39: "...there is less learner involvement in the class. No appropriate reinforcement was given when a learner answers a question."
}

Some comments by peers and university educators (except one university educator who indicated thinking time as important) indicated merely the positive areas of student teachers' performance during the lesson presentation. No areas for improvement were indicated. Some of their comments are as follows:

P2: "He involved learners and learners ask questions and the educator was able to offer feedback."

U2: "Motivated students to answer questions by applauding the correct answers. Allow learners to think about the question asked."

U11: "Class involvement is good and complement to learners."

U22: "It's quite commendable to call four learners by their real names."

All the assessor groups had members who indicated areas that the student teachers needed to improve during their presentations. Some of the comments representative of what they said are the following:

M28: "Avoid answering questions from [for] learners. Involve them in answering questions."

M38: "You need to be developed how to discipline learners.... Allow learners to ask questions."

P18: "The educator should develop his listening skills towards the learners."

P34: "He must try to make all learners to participate. Give the learners a chance to express themselves."

U7: "Learners are individuals; you should be able to identify those who are struggling with concepts."

U18: "Teaching pace: don't be fast for slow learners. Don't just assume that learners understand, you have to give them questions." 
Most of the comments from all assessors indicate that teaching should be learner-centred rather than teachercentred. This is also a requirement of the curriculum of the country.

\subsection{Teaching Strategies (TS)}

\subsubsection{Questioning strategy}

One of the preferred teaching strategies assessed by the mentors, peers, and university educators is questioning, which is appropriate for learner-centred approaches. The following excerpts reflect the assessments:

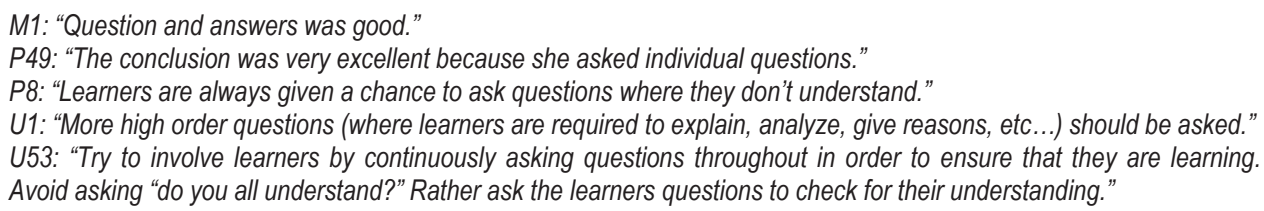

All the assessors evaluated this teaching strategy very well because they not only praised the student teachers; they also indicated areas where the teaching strategy was not utilized and offered suggestions on how it could be implemented.

\subsubsection{Other teaching strategies}

For the entire student teacher assessment process, this subsection is the most dominant. This shows that most of the assessors value teaching strategies as the most important aspect of the teaching practicum. We say this because most assessors said something about how a student teacher taught or should have taught. For instance, in this sub-section the frequencies show that there was one comment from each university educator. Besides praising student teachers for good teaching, all assessors criticised the lessons and provided fruitful feedback. Some of the comments representing all assessors are as follows:

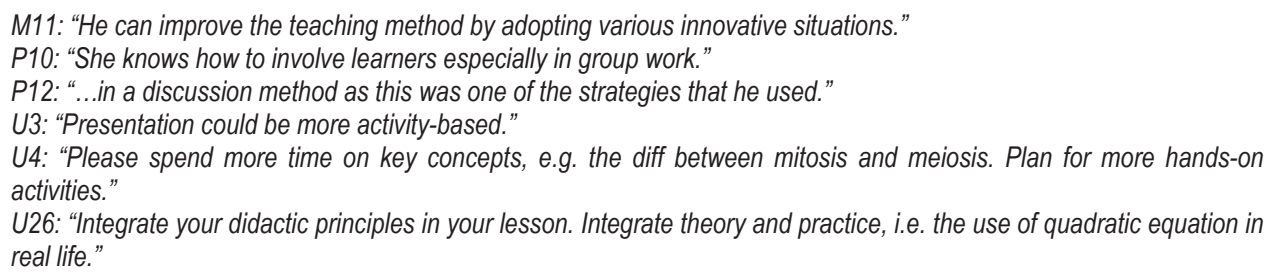

What also emanates from the above comments is that the assessors value learner-centred teaching.

\subsubsection{Lesson plan and presentation}

The only assessors who commented about the lesson plan and how it related to presentation were the mentors. We think the reason may be that the Department of Basic Education of South Africa expects them, through the curriculum, to prepare a lesson plan and present accordingly. Some of their comments are as follows:

M20: "His lesson planning and presentation are up to standard."

M44: "I have observed different kind of things including presentation of the lesson which was very interesting in terms of methodology."

\subsubsection{Lesson outcomes}

Three peers assessed the student teachers' lessons and pointed out issues relating to lesson outcomes. They may have assessed the learning outcomes because they are expected to include the learning outcomes in their lessons when they teach. Although the mentors and university educators did not assess lesson outcomes, this may be implicit in different 
areas of their assessment, for example when an assessor indicates that a student teacher did not ask questions at the end of a lesson. The peers' comments are as follows:

P29: "Learning outcomes was not clear."

P39: "...and outcomes clearly outlined."

P47: "Lesson outcomes were achieved."

\subsection{Subject Matter Knowledge}

In the present study, as in many institutions, the summative assessment (supervision) of practicum was conducted by university staff who were neither familiar with science content "nor the epistemic underpinning of reformed" science teaching and learning (Manouchehri, 2002, p.736). As long as content knowledge is important for teaching any particular subject matter in the classroom (Hudson, 2013), assessment would also be valuable if done by an assessor with relevant subject matter knowledge. Below is some indication of how assessors assessed SMK.

\subsubsection{Topic-specific subject matter knowledge (SMK)}

Only one mentor provided a comment that indicated topic-specific SMK. None of the peers specified a topic/ concept when assessing student teachers. Nine university educators managed to comment about the SMK of the teacher. Some of the comments are:

M48: "Explain where is ( $\mathrm{x}$ ) used and for what. BODMUS rule - define terms denominator, numerator."

U11: "Define the terms parallel, $V, R$, potential difference, EMF."

The dominant group in commenting about topic-specific SMK comprises university educators (six). This reflects the qualifications of the assessors of the student teachers.

\subsubsection{Non-topic specific SMK}

Most of the comments provided by the assessors were not topic-specific. This is no surprise since most peers and university educators were not subject specialists. A reflection of how the assessors commented without mentioning concepts is presented below.

M7: "the educator is well grounded in the knowledge and content of the subject. He clearly explains the concepts."

P41: "you are confident and seem knowledgeable about the subject content. He has knowledge of the content."

U8: "Educator is confident and has knowledge about subject matter."

\subsection{Classroom Management (CM)}

Student teachers in the study by Bailey et al. (1999) indicated that classroom management and disciplinary procedures were the most important issues in defining good teaching. They also pointed out that wait time (time taken for a learner to think before responding) might jeopardise the order in the classroom. Although they found classroom management to be a priority, student teachers classified wait time as a problem because they were still in their formative years and might not have understood how to handle this issue (Hudson, 2013). Taskin (2006) found that when learners answered questions in class student teachers viewed this as being respectful. However, when they were not well behaved, student teachers found that classroom management was negatively affected (Taskin, 2006). Below we present and discuss what was evaluated by the assessors.

\subsubsection{Good/ bad classroom management - Mentors (6/9); Peers (6/14); University educators (2/13)}

Four mentors indicated that the student teacher managed the class well, while the fifth mentor (M22) indicated that the student teacher should start to control the class. Although M22 did not indicate exactly what the problem was in the class, we suspect that it could have been the issue of 'wait time', which was also reported to be a problem in Hudson's (2013) study. It may also be that the learners were not well behaved (Taskin, 2006). The comments from the mentors are: 
M2: "Could create a good learning and teaching atmosphere."

M15: "Generally she handled classroom management and control very well."

M22: "She is good in her class but there are some problems she facing like controlling the class."

Two peers, P2 and P13, indicated the areas of improvement as being in control of the class and being confident. The other four peers just indicated that the class was well managed without indicating areas for improvement.

Although most teacher education programmes expect to produce teachers who, besides being knowledgeable (Smith \& Lev-Ari, 2005), also "master the more technical aspects of teaching such as classroom management" (p.290), in this study only one university educator commented about classroom management. University educator U10 indicated that the classroom management was good and that the student teacher should make sure that learners were more involved.

\subsubsection{Learners' behaviour}

Some of the assessors who did not explicitly mention classroom management as part of their comments did so by indicating issues relating to learners' behaviour. Peers were the dominant contributors in terms of commenting about classroom management. This is similar to the study of Bailey et al. (1999), which indicated that student teachers valued classroom management. The mentors' comments were about making sure that there was discipline in class.

Four of the five peers who commented warned the student teachers about lack of control in their classes and suggested that they should improve. For example, P18 said, "The educator gave learners class work and few of learners didn't write it. He must improve punishment." The fifth peer, P25, commented, "The learners' behaviour was properly managed."

All six the university educators who commented about learners' behaviour indicated that the student teachers should improve the control of learners in the classroom. For instance, two university educators commented as follows:

U39: "...attend to all the learners in class and don't neglect those who are on your right hand side."

U46: "However, consider the following: avoid chorus answers."

\subsubsection{External factors}

One peer indicated that the student teachers should improve their management skills. The peer failed to indicate exactly which skills the student teacher should improve. Only two university educators commented on external factors. One of them indicated that the student teacher should "try to be as resourceful as possible" without indicating what exactly the student teacher should do to be resourceful. The second university educator's comment was about making sure that the noise coming from outside the classroom did not interfere with the lesson, as indicated below.

\section{U47: "Close the door for all the noise."}

\subsection{Linking Topics or Lessons (LTL)}

In the study conducted by Hudson (2013), mentors believed that if student teachers could make explicit how the present lesson was linked to previous learning, this would aid them in lesson implementation. In this study, the peers of student teachers provided the most comments about introducing the lesson and linking it to previous knowledge. Mentors and university educators also provided useful comments that could aid in the development of the student teachers. Some of the comments from mentors, peers, and university educators are as follows:

\footnotetext{
M48: "Introduction was good could you increase the example in future to link to the past and show the relevance of the topic."

M21: "She needs to link her lesson with previous lessons."

P14: "...but first get their attention by asking them questions that will connect them to the topic of the day."

$P 20$ : "It is also important to integrate content taught with other learning areas."

U2: "The student linked prior knowledge with new knowledge."

U4: "No indication of a precise link with previous lesson, or any integration with other learning areas."
}

\subsection{Lesson Plan (LPN)}

Most teacher education programmes expect to produce teachers who are both knowledgeable (Smith \& Lev-Ari, 2005) 
and "master the more technical aspects of teaching such as ... good lesson planning" (p.290). In this study, unsurprisingly most of the comments about lesson planning were by university teacher educators who were active in a teacher education programme. Mentors and peers commented less frequently about the student teachers' lesson plans. The peers did not see any problem areas that needed improvement with the lesson plans. One mentor (M26) indicated that the lesson design should be improved. Six university educators indicated areas that needed improvement.

\subsection{Mentors' Syllabus/ Curriculum (SC) (6/53)}

Although the student teachers are taught about curriculum at university, there was no evidence of assessing it from the peers and university educators. It could be that they value the intended but not the enacted curriculum. In fact, Hudson (2013) reported about mentors and mentees deliberating about planning and actual implementation of the curriculum. The mentors' comments that were informed by knowledge of the curriculum were as follows:

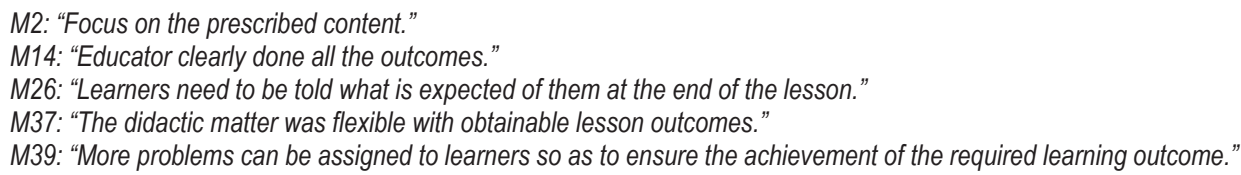

\subsection{Time Management (TM)}

All the assessors commented constructively about how student teachers managed time.

\subsection{Voice Level (VL)}

Few comments came from each assessor group. The assessors' reports indicated that the voice level was either too loud or not loud enough.

\subsection{Introduction (INT)}

Four mentors indicated that the lesson was introduced well. One peer indicated that the lesson introduction needed improvement while the other ten indicated the lessons were introduced well. Eight of the twelve university educators felt that the lessons were either not introduced or they needed improvement, such as making sure that learning outcomes were indicated at the beginning of the lesson.

\subsection{Student Teacher Appearance (STA)}

The appearance of student teachers is assessed and marks are awarded during teaching practicum. However, few assessors (three mentors, one peer and four university educators) commented on this item. All the assessors' comments were positive and could be represented by $\mathrm{U} 29$ as follows:

U29: "Well groomed teacher who portrayed acceptable conduct." (STA)

\subsection{Lesson Presentation (LP)}

The assessors' comments were all positive about how the student teacher presented the lesson. Only one mentor commented about lesson presentation. The comments from each assessor group can be summarised by the comments below.

M48: "The lesson was well presented."

P39: "...great lesson presentation."

U36: "Lesson preparation and presentation were done very well."

\subsection{Media Usage (MU)}

Learners' participation, discipline and self-confidence were thought to be the result of the use of media by student 
teachers in Taskin's study (2006). In the same study, Taskin reported that most student teachers indicated that they did not use materials while teaching. It is also evident in the present study that most student teachers did not use materials/ media.

Only two mentors and five peers commented about the use of media by student teachers. Except for one comment by a mentor (M8), indicating that the student teacher used charts, the other mentor's and peers' comments indicated that there was a lack of media use by student teachers, as shown below.

\section{M21: "The student teacher also needs to bring more teaching media into the classroom in order to enhance teaching and learning." \\ P11: "The teacher must learn to use more teaching media and writing on the board."}

Three university educators, U16, U17 and U39, applauded the student teachers for using media efficiently. The rest of university educators raised areas for improvement in terms of media usage during teaching.

\subsection{Assessment (AS)}

Student teachers view answering of questions by their learners as good behaviour (Taskin, 2006). In this paper, peers did not comment about assessment in their judgement of the student teachers' lessons. This does not mean that there was nothing to say about how the student teachers assessed during their lessons. In fact, one mentor (M45) and seventeen university educators suggested some improvements relating to assessment that student teachers should consider during their lesson presentations. As in Hudson's study (2013) about mentors, a mentor and university educators in the present study "signalled the use of teacher and student-generated questioning to check for understanding" (p.12). Only university educator U34 mentioned Bloom's taxonomy under Assessment. Hudson (2013) points out that the development of "effective questioning skills (e.g. Bloom's taxonomy)" (p.15) is necessary to facilitate classroom management.

\subsection{Language (LAN)}

None of the mentors commented about language usage, probably because they spent time with the student teachers at school during the teaching practicum period. Four peers commented about how student teachers communicated using the medium of instruction. Peers P2 and P5 said: "Pay attention [to] language usage" and "...but she have improve her pronunciations of words" respectively. Their comments are important because they are intended to develop the student teachers' practice. It is also important for assessors to indicate if the student teachers have used the language well since this motivates them to do so in future. Two peers, P10 and P53, said, "She has a good communication skill" and "...and the medium of instruction was excellent" respectively. Five comments about language usage were provided by four university educators. Four of the five comments were to encourage student teachers to improve their language usage and one comment was just praise for commanding the language well.

\section{Conclusion}

\subsection{Research Question 1}

What are the key pedagogical issues that emanate from the peers', mentors', and university educators' assessment of the student teachers teaching?

Besides praising fellow student teachers, peers did not have an area where they were dominant in terms of comments relating to peer teaching. Mentors seem to be more informed and concerned about the implementation of the curriculum. This was evident when mentors were the only assessors who commented on the curriculum during their observation of student teachers' lessons. Mentors were also the only assessors who commented about lesson planning and how it related to presentation. This is perhaps because the Department of Basic Education of South Africa, during curriculum training programmes, expected teachers to prepare a lesson plan and present accordingly. In Hudson's (2013) study, mentors and student teachers deliberated about planning and actual implementation of the curriculum. This may mean that the mentors' comments are informed by their knowledge of the curriculum they interact with in their every day teaching activities.

University educators suggested some improvements in terms of how student teachers assess in their lessons, whereas mentors and peers did not seem to see the value of assessment. In agreement with the study by Bailey et al. 
(1999), student teachers in the present study were the dominant contributors in terms of comments about classroom management.

\subsection{Research Question 2}

Whose assessment is important in making sure that the student teacher develops into a quality teacher?

University educators and mentors had more to say about learner knowledge and teaching strategies. Although not topic-specific, university educators also provided some comments relating to subject matter knowledge. We propose that in the absence of properly qualified discipline specific mentors, available mentors undergo some workshops or training on subject matter knowledge. This could complement university educators in accurate summative assessment. Peers are however focused on praising student teachers and indicating how ready they are for their future careers. Peers can therefore be helpful in terms of motivating student teachers in formative assessment.

\section{References}

Bailey, B. L., Scantlebury, K. C., \& Johnson, E. M. (1999). Encouraging the beginning of equitable science teaching practice: Collaboration is the key. Journal of Science Teacher Education, 10(3), 159-173.

Brooker, R., Muller, R., Mylonas, A., \& Hansford, B. (1998). Improving the assessment of practice teaching: A criteria and standards framework. Assessment and Evaluation in Higher Education, 23(1), 5-24.

Ezer, H., Gilat, I., \& Sagee, R. (2010). Perception of teacher education and professional identity among novice teachers. European Journal of Teacher Education, 33(4), 391-404.

Fives, H., Hamman, D., \& Olivarez, A. (2007). Does burnout begin with student-teaching? Analyzing efficacy, burnout, and support during student-teaching semester. Teaching and Teacher Education, 23, 916-934.

Fung, L., \& Chow, L. P. Y. (2002). Congruence of student teachers' pedagogical images and actual classroom practices. Educational Research, 44(3), 313-321.

Harford, J., \& MacRuairc, G. (2008). Engaging student teachers in meaningful reflective practice. Teaching and Teacher Education, 24, 1884-1892.

Hascher, T., Cocard, Y., \& Moser, P. (2004). Forget about theory - practice is all? Student teachers' learning in practicum. Teachers and Teaching: Theory and Practice, 10(6), 624-637.

Hudson, P. (2013). Strategies for mentoring pedagogical knowledge. Teachers and Teaching: Theory and Practice, 19(4), 363-381.

Hyland, F., \& Lo, M. M. (2006). Examining interaction in the teaching practicum: Issues of language, power and control. Mentoring and Tutoring, 14(2), 163-183.

Kirbulut, Z. D., Boz, Y., \& Kutucu, E. S. (2012). Pre-service chemistry teachers' expectations and experiences in the school experience course. Australian Journal of Teacher Education, 37(2), 41-57.

Leshem, S. (2012). The many faces of mentor-mentee relationships in a pre-service teacher education programme. Creative Education, 3(4), 413-421.

Manouchehri, A. (2002). Developing teaching knowledge through peer discourse. Teaching and Teacher Education, 18, 715-737.

Murray-Harvey, R., Slee, P. T., Lawson, M. J., Silins, H., Banfield, G., \& Russell, A. (2000). Under stress: The concerns and coping strategies of teacher education students. European Journal of Teacher Education, 23(1), 19-35.

Orland-Barak, L. (2002). The impact of the assessment of practice teaching on beginning teaching: Learning to ask different questions. Teacher Education Quarterly, 29(2), 99-122.

Patrick, R. (2013). "Don't rock the boat": Conflicting mentor and pre-service teacher narratives of professional experience. The Australian Educational Researcher, 40(2), 207-226.

Poulou, M. (2007). Student-teachers' concerns about teaching practice. European Journal of Teacher Education, 30(1), 91-110.

Sedumedi, T. D. T., \& Mundalamo, F. J. (2012). Understanding field assessment of pre-service teachers on school practicum. Africa Education Review, 9(S1), S73-S90.

Sinclair, C., Munns, G., \& Woodward, H. (2005). Get real: Making problematic the pathway into the teaching profession. Asia-Pacific Journal of Teacher Education, 33(2), 209-222.

Smith, K. (2007). Empowering school- and university-based teacher educators as assessors: A school-university cooperation. Educational Research and Evaluation, 13(3), 279-293.

Smith, K., \& Lev-Ari, L. (2005). The place of the practicum in pre-service teacher education: The voice of the students. Asia-Pacific Journal of Teacher Education, 33(3), 289-302.

Tang, S. Y. F. (2008). Issues in field experience assessment in teacher education in a standards-based context. Journal of Education for Teaching, 34(1), 17-32.

Taskin, C. S. (2006). Student teachers in the classroom: Their perceptions of teaching practice. Educational Studies, 32(4), 387-398.

Ulvik, M., \& Sunde, E. (2013). The impact of mentor education: Does mentor education matter? Professional Development in Education, $39(5), 754-770$. 